Abstracta Iranicacta Iranica

Revue bibliographique pour le domaine irano-aryen

Volume 32-33 | 2013

Comptes rendus des publications de 2009-2010

\title{
Andrea Gariboldi. Social Conditions in Egypt under the Sasanian Occupation (619-629 A.D.)
}

\section{Rika Gyselen}

\section{(2) OpenEdition}

1 Journals

Édition électronique

URL : http://journals.openedition.org/abstractairanica/40492

DOI : 10.4000/abstractairanica.40492

ISSN : 1961-960X

\section{Éditeur :}

CNRS (UMR 7528 Mondes iraniens et indiens), Éditions de l'IFRI

\section{Édition imprimée}

Date de publication : 1 décembre 2013

ISSN : 0240-8910

\section{Référence électronique}

Rika Gyselen, « Andrea Gariboldi. Social Conditions in Egypt under the Sasanian Occupation (619-629 A.D.) ", Abstracta Iranica [En ligne], Volume 32-33 | 2013, document 154, mis en ligne le 01 juillet 2016,

consulté le 26 septembre 2020. URL : http://journals.openedition.org/abstractairanica/40492 ; DOI : https://doi.org/10.4000/abstractairanica.40492

Ce document a été généré automatiquement le 26 septembre 2020.

Tous droits réservés 


\title{
Andrea Gariboldi. Social Conditions in Egypt under the Sasanian Occupation (619-629 A.D.)
}

\author{
Rika Gyselen
}

\section{RÉFÉRENCE}

Andrea Gariboldi. « Social Conditions in Egypt under the Sasanian Occupation (619-629

A.D.) ». Avec un Appendix par A. Soldati, La Parola del Passato. Rivista di Studi Antichi, CCCLXVIIII, Napoli, 2009, p. 321-353.

1 Après une brève évocation des péripéties qui ont mené à l'occupation sassanide de l'Égypte (619-629), AG aborde: I. Les événements d'après les sources littéraires, et II. Les informations fournies par les papyri et leur interprétation.

2 En s'appuyant sur des sources souvent contemporaines des événements, l'A. décrit comment les Sassanides parviennent à établir leur domination en Égypte. Également très familier avec la bibliographie récente sur laquelle il émet parfois des observations pertinentes, l'A. offre un chapitre très instructif sur cette tranche de l'histoire sassanide.

De cette période d'occupation sassanide datent de nombreux papyri, en grec, copte et pehlevi, dont certains jettent une lumière sur les pratiques économiques et fiscales de cette époque. Le responsable sassanide qui perçoit les diverses taxes et les fait parvenir à Khusro II s'appelle Šahrālānyōzān. D'après AG ce personnage aurait pu aussi être le commandant des forces militaires sassanides en Égypte. Les papyri mettent aussi en évidence que les Sassanides se sont adaptés aux normes locales des poids et mesures, ainsi que pour les moyens de paiement. 


\section{AUTEURS}

\section{RIKA GYSELEN}

CNRS/Mondes iranien et indien, Paris 